\title{
Review of the Protocol for Evacuation and Transfer of Patients in the Intensive Care Unit in Disasters
}

\author{
*Hazrati. E1 \\ Mosaed. $\mathrm{R}^{2}$ \\ Hamidi Farehani. $\mathrm{R}^{3}$ \\ Rajabi. J3 \\ Akhavan Rezayat. $A^{4}$ \\ 1- ( ${ }^{*}$ Corresponding Author) \\ Associate Professor, \\ Anesthesiology and critical care \\ Department, Aja University of \\ Medical Sciences, Tehran, Iran. \\ Email:dr.hazrati.e@gmail.com \\ 2- MD, Clinical Pharmacology, \\ Assistant Professor, Clinical \\ Pharmacy Department, Faculty \\ of Medicine, Aja University of \\ Medical Sciences, Tehran, Iran. \\ 3- Assistant Professor, Infectious \\ dieases Department , Aja \\ University of Medical Sciences, \\ Tehran, Iran. \\ 4- MD, Centre for Infectious \\ Disease, Aja University of \\ Medical Sciences, Tehran, Iran.
}

\begin{abstract}
Introduction: Natural or human-made disasters are the main reasons for hospital evacuation. Health officials must pre-plan hospital programs for complete or partial evacuation and establish an optimal management structure for the area of operation. In the present study, we outlined some points for dealing with the possibility of hospital discharge. Despite the high risk of the evacuation of intensive care units in crises, service providers in these wards unfortunately do not receive adequate training on the safe and effective evacuation of intensive care units.

Objective: The present study aimed to determine the extent of readiness of hospitals to evacuate and transfer patients hospitalized in the intensive care unit in accidents and disasters.
\end{abstract}

Materials and Methods: In the present review study conducted in 2019, a protocol for evacuating patients in the intensive care unit during disasters has been studied. PubMed and Scopus databases were reviewed. For this purpose, the keywords Disaster, Evacuation, and Intensive Care Unit were used. Then, databases were searched with the help of keywords.

Results: In the present study, fifteen steps have been considered for before, during, and after the evacuation of an intensive care unit during disasters. These steps are introduced as a protocol according to the papers reviewed.

Discussion and Conclusion: While patients are at risk, the hospital manager often decides on how evacuate facilities for protecting patients and staff. Hospital evacuation had a dramatic effect on staff, family members, the community, and even the country, as well as the consequences for patients. Successful evacuation of the ICU in the event of a disaster requires readiness, participation, effective communication, and leadership by special care providers.

Keywords: Disaster, Intensive Care Unit, Transport. 


\title{
آمادكى بيمار ستانها جهت تخليه و انتقال بيمار ان بخش مراقبتهاى ويزٔه در حوادث و بلايا
}

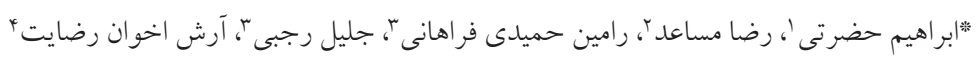

جكيده

مقدمه: بلاياى طبيعى و انسانى مانند جنگ، سيل و زلزله از دلايل اصلى تخليه بيمارستانها مى باشند. در اين بحرانها،

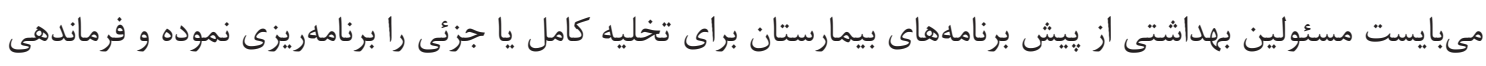

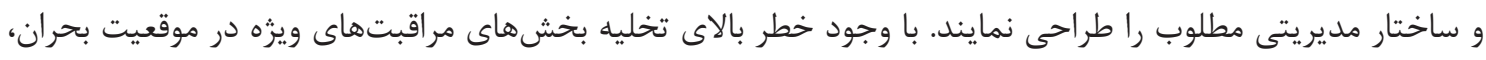

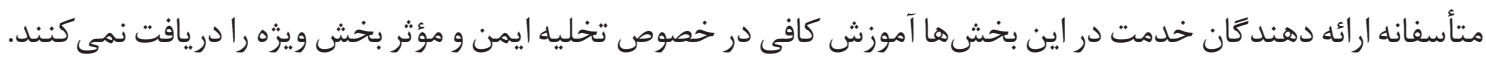

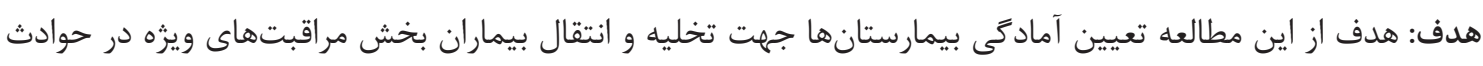
و بلايا مىباشد. مواد و روشها: در اين مطالعه مرورى كه در سال ^وس ا انجام شد، به بررسى يروتكلهاى مرتبط با تخليه بيماران بخش

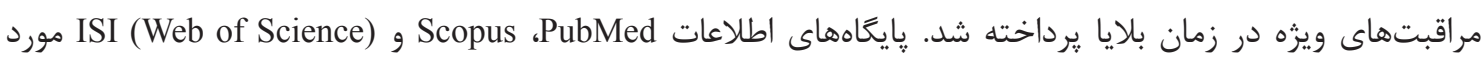

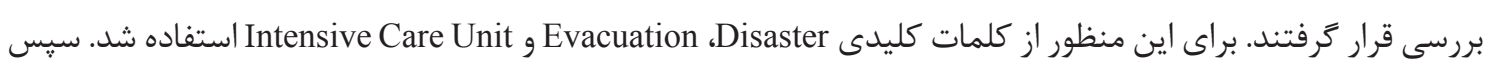

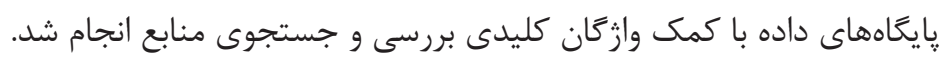

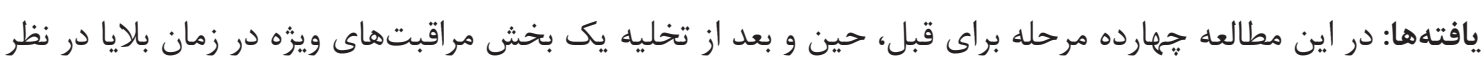

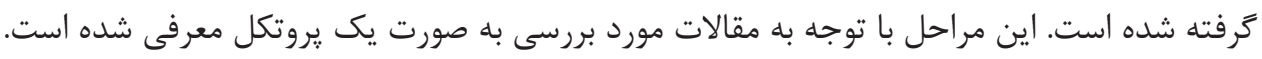

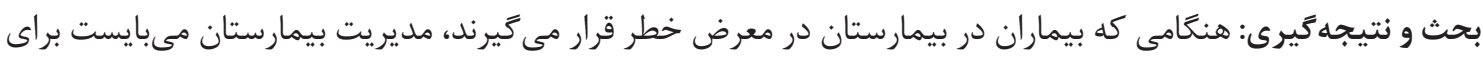

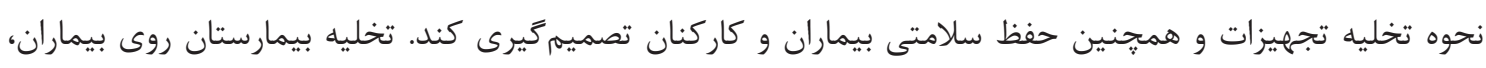

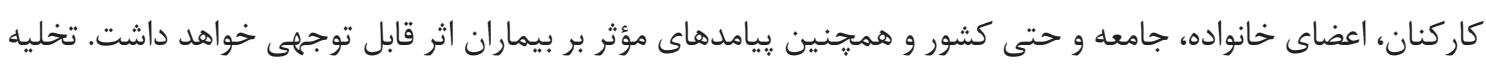

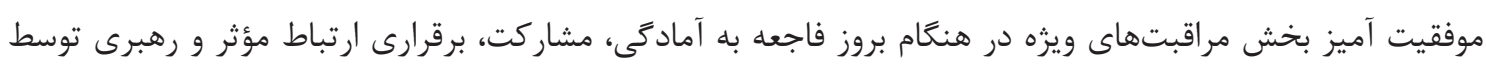

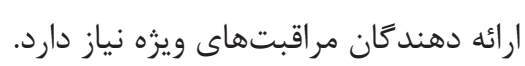

كلمات كليدى: انتقال، بخش مراقبت ويزه، بلايا.

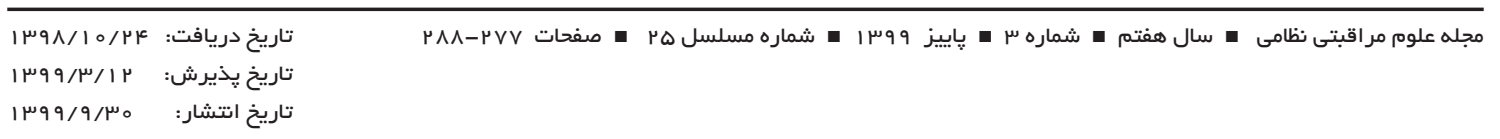

زلزله و سيل هستند (ז). بلاياى اخير نشان داده است كه واحدهاى

مقدمه

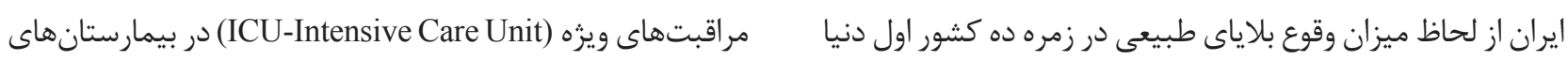

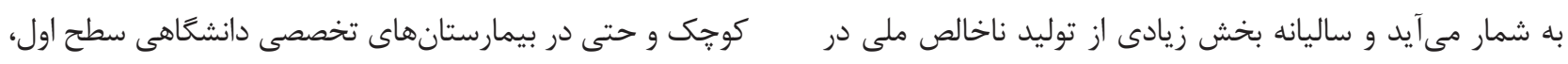

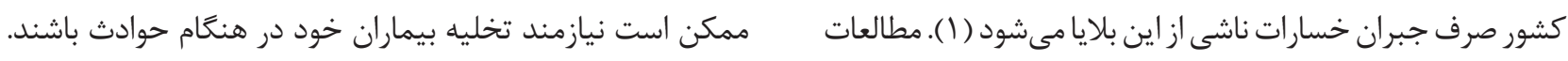

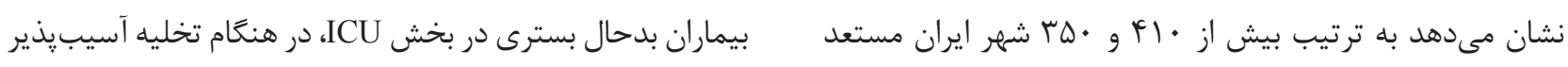


شده است. پايكاههاى اطلاعات PubMed و Scopus و ISI (Web مورد بررسى قرار كرفتند. براى اين منظور از كلمات of Science) كليدى Evacuation ، Disaster و و استفاده شد. سيس پايعاههاى داده با كمك وازَّان كليدى بررسى و

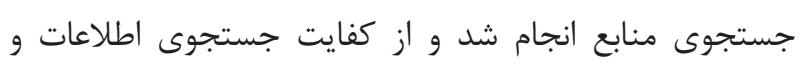

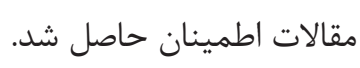

يافتهها در اين مطالعه \&|f مرحله به منظور تخليه ايمن بيماران بخش

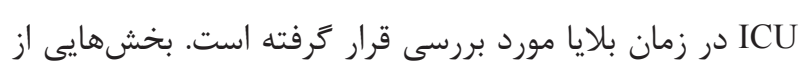
اين :روتكل با كمك كايدلاين كالج آمريكايى متخصصان قفسه

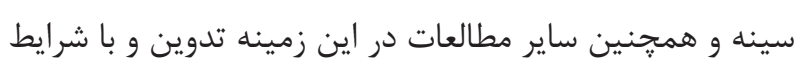

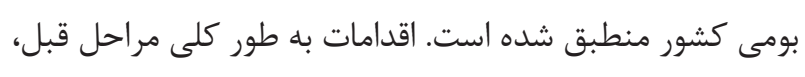

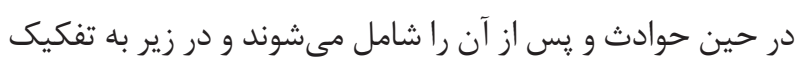
بيان شده است.

\section{ا. موافقت نامه بين بيمارستان و سيستم حمل و نقل}

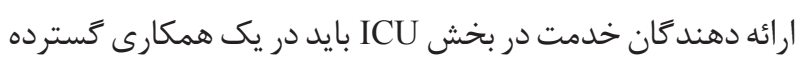

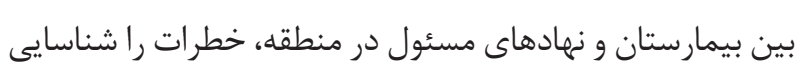
كنند و يك برنامه عملى براى تخليه در بيمارستان خود ايجاد

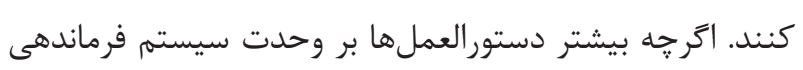
براى اخذ تصميمات در هنعام تخليه تمركز دارند، ولى بايد در

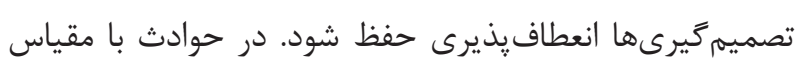

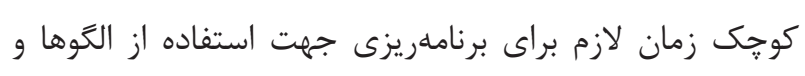

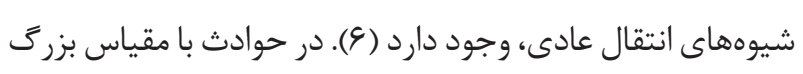

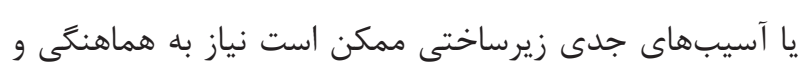

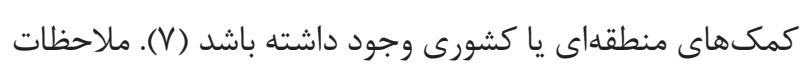

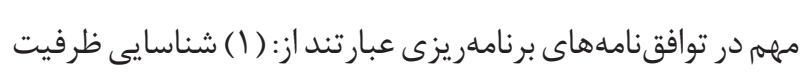
مراقبت ويزه منطقه و تجهيزات موجود در منطقه (N)، (؟) تعيين قبلى و استقرار متمركز و هماهنتَ حمل و نقل زمينى و هوايى

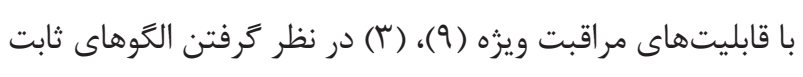

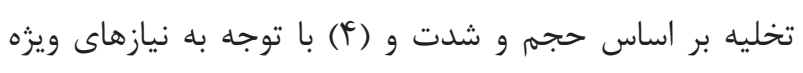

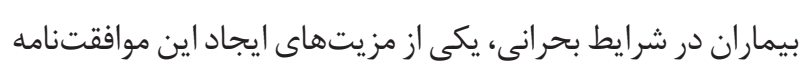

هستند زيرا از لحاظ يزشكى ضعيف بوده و نيازمند امكانات و متخصصان ويزه هستند. سيستم انتقال معمولى روزانه بيماران

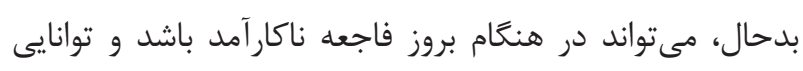

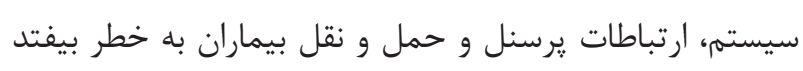

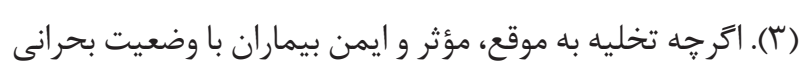

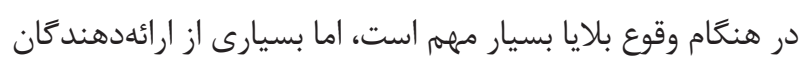

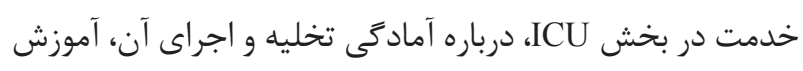

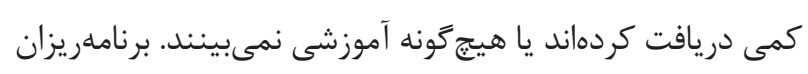

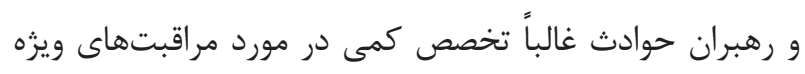

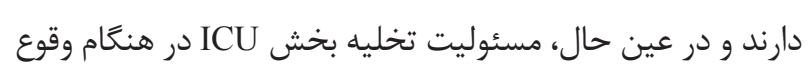

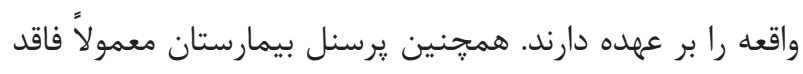

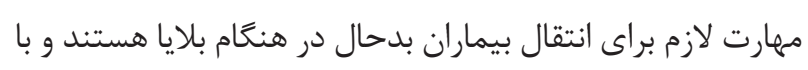
بسيارى از نكات لازم در مورد مراقبت اين بيماران ناآشنا هستند.

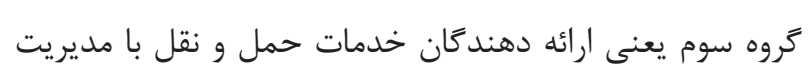
بيمار بدحال در حين بلاياو در شرايط غيرعادى ناآشنا هستند و از

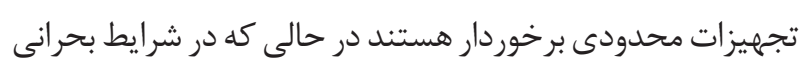

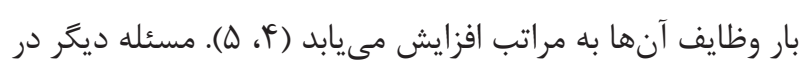
مورد تخليه بخش ICU مراكز دانشكاهى سطح يك است اين مراكز

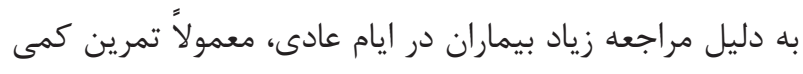

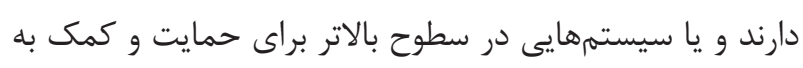

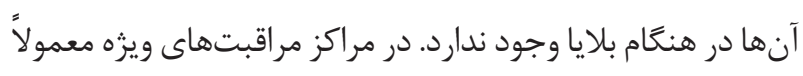

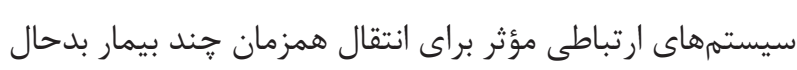
در شرايط بحرانى ايجاد نشده است و ممكن است برقرارى ارتباط دئل

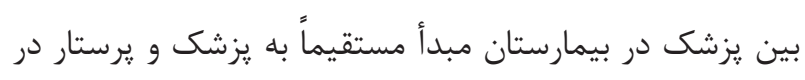

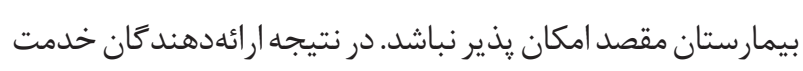

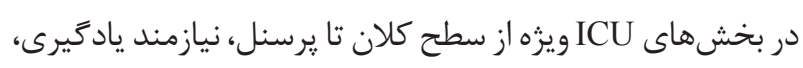

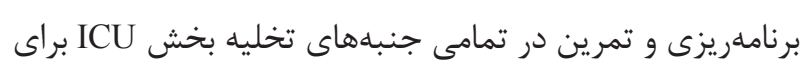

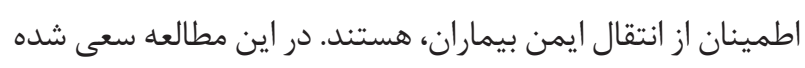

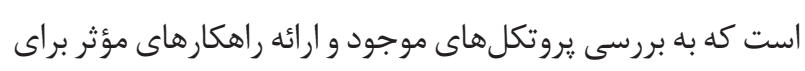
تخليه بخش ICU بيمارستانها در هنغام بروز بلايا يرداخته شود.

\section{مواد و روشها - - ماد}

در اين مطالعه مرورى كه در سال هوبا انجام شد به بررسى

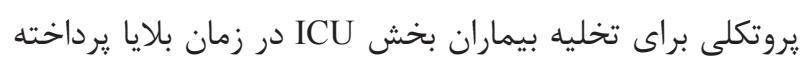


منابع مشخص منجر به كاهش قابل ملاحظه در نظارت بر بيمار و

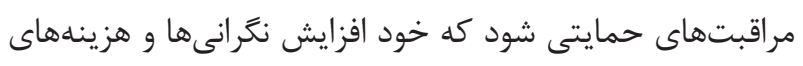

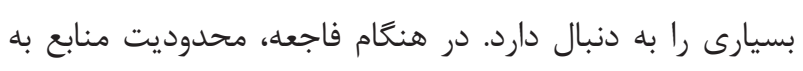

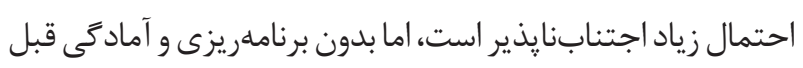

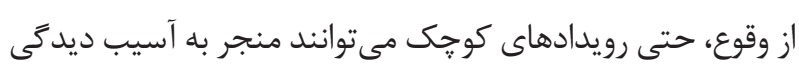
بيشتر بيماران به دليل تخصيص ضعيف منابع شوند. مثال رهاى

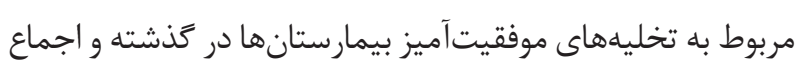
نظر متخصصين به اين نكته اشاره دارد كه استفاده از يك سيستم

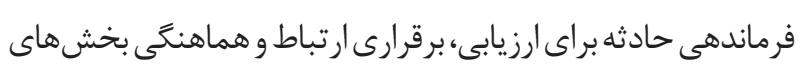

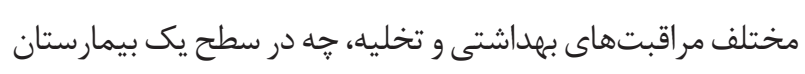

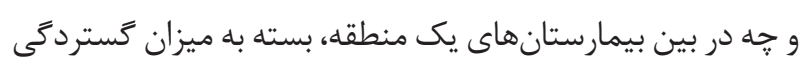

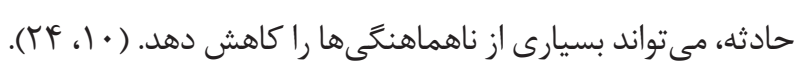

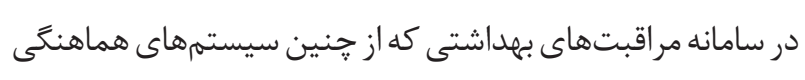
به عنوان بخشى از برنامههاى روزمره خود استفاده نمى كنند، بايد

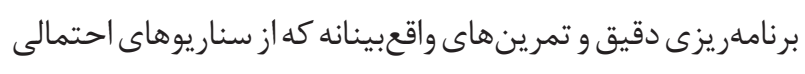

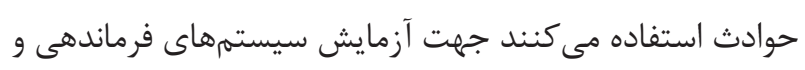

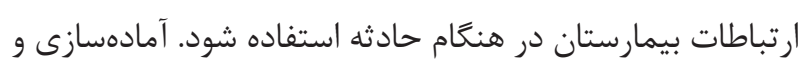
حمل و نقل بيماران شبيهسازى شده بايد با استفاده از تجهيزات

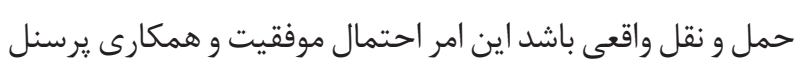
را در سطح سيستم در هنكام حادثه افزايش مى دهدي. حوزهمايى

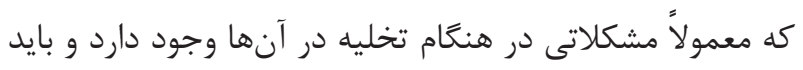

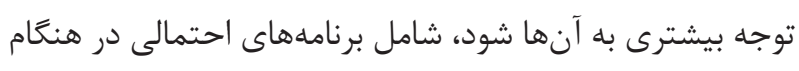

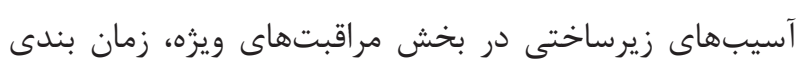
تخليه، روش انجام تخليه (از جمله برنامه تخليه عمودى)، توزيع دئ دئي

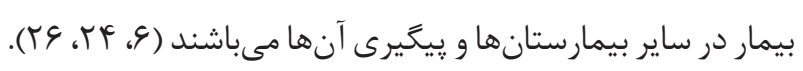
فاجعه يازده سيتامبر كمبود منابع يزشكى كودكان در مقايسه

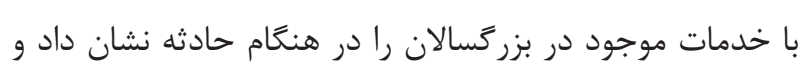

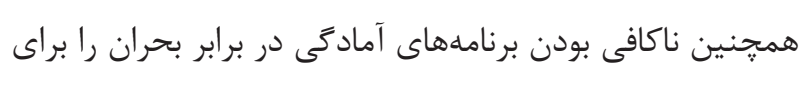

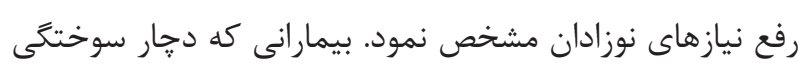

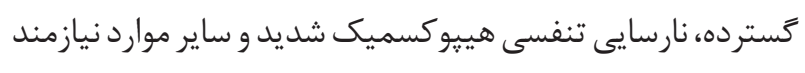
به فن آورى ييشرفته براى مراقبت مداوم هستند نياز به ملاحظات

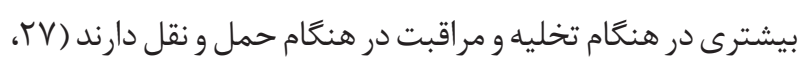

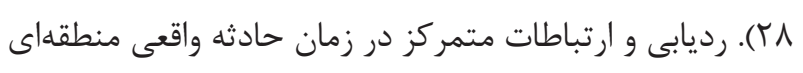

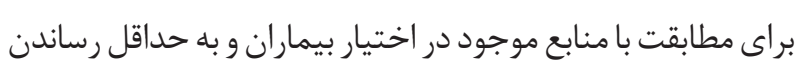

از مراكز دولتى مانند شهردارىها استفاده كنند. اين مراكز با شناسايى بيمارستانهاى كرفتار بهترين خدمات را ارائه مى كنند

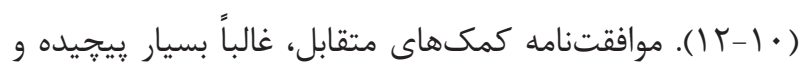
داراى جزييات زيادى هستند؛ بنابراين، مههم است كه اين موارد ماد

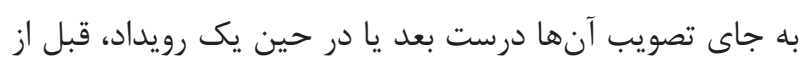

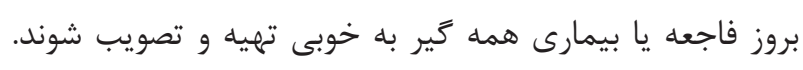

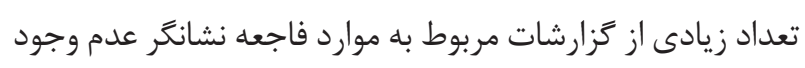

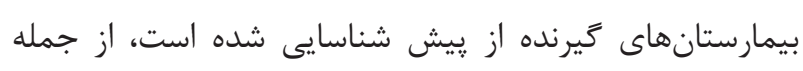
اين موارد مىتوان فاجعه 11 سيتامبر، طوفان كاترينا، بحران

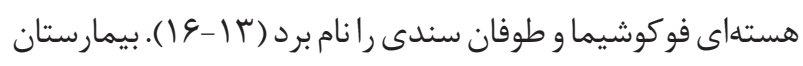
و نهادهاى بهداشتى و درمانى منطقهاى بايد در صورت امكان،

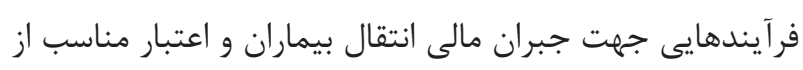

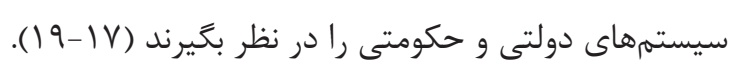

\section{r. آمادهسازى و شبيه سازى تخليه بيماران مراقبتهاى ويزه}

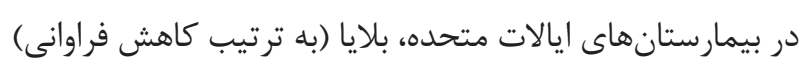

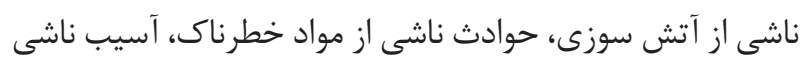

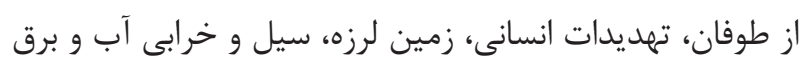

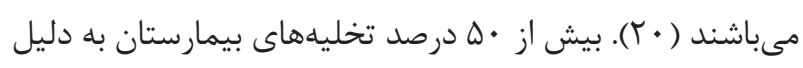

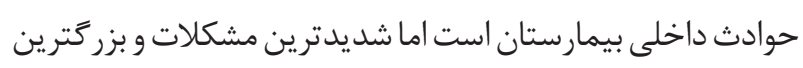

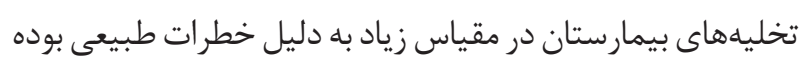

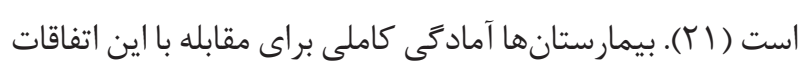

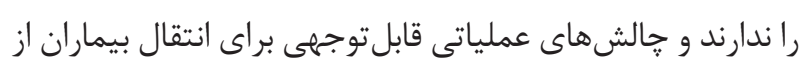
مناطق مختلف بيمارستان به طبقه همكف براى تخليه يا براى ايجاد

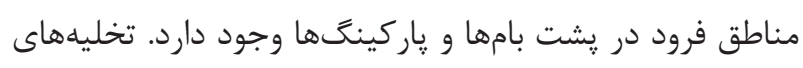

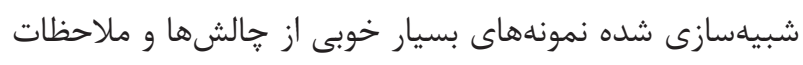

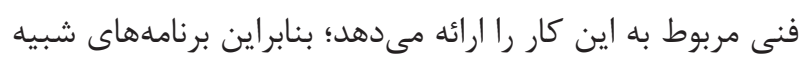

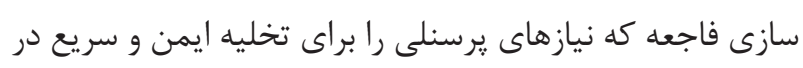

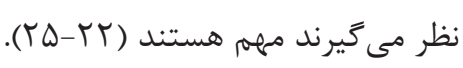

r. آمادكى و شبيهسازى انتقال بيماران مراقبتهاى ويزه كزارشهاى متعددى خطرات برنامهريزى و هدايت برنامههاى

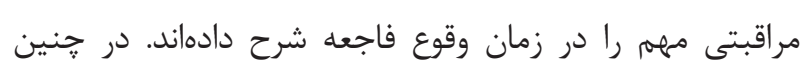

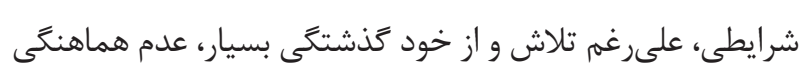


منابع مورد نياز ( ICU (ICU، مهارتهاى مورد نياز جهت حمل و نقل

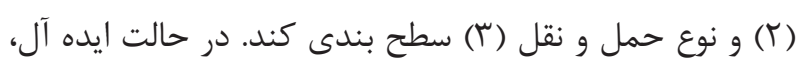

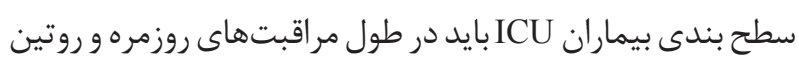
انجام شود و اطلاعات در يك جى ليست ليست الكترونيكى وارد شوند.

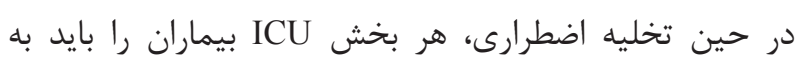

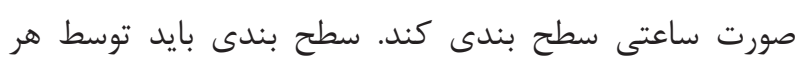

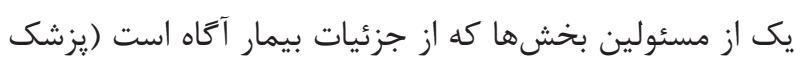

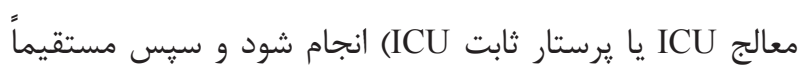

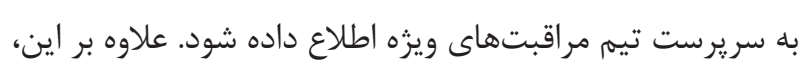

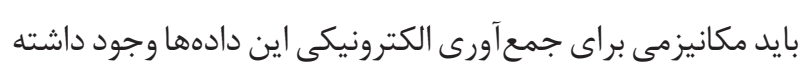

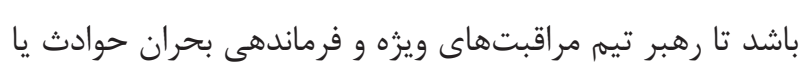
بلايا بتواند بلموقع از وضعيت ICU آكاهى يابد (سب).

\section{צ. برنامدريزى اقدامات لازم براى تخليه اضطرارى قبل از وقوع}

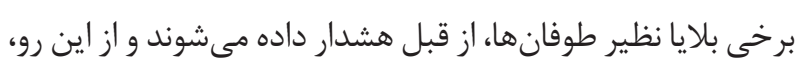
اقدامات لازم براى تخليه اضطرارى قبل از وقوع فاجعه را مىتوان

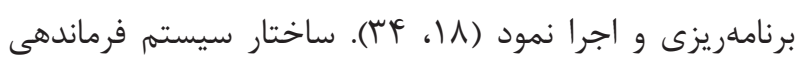
بحران حوادث بايد فعال شود و منابع موجود در بيمارستان، از جمله مواد غذايى، آب، زنراتورهاى امدادى، كارمندان و تجهيزات

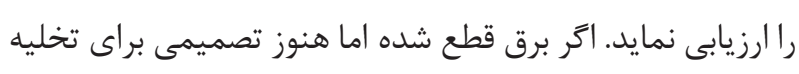

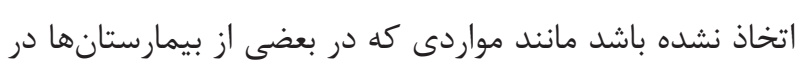
طول حوادث طبيعى مثل طوفان سندى (Sandy) اتفاق افتاد،

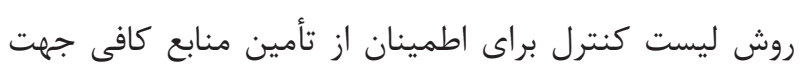

$$
\text { ICU }
$$

سريرست تيم تخليه بخش ICU مىبايست قبل از اعلام رسمى

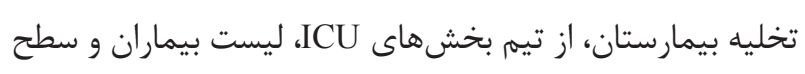

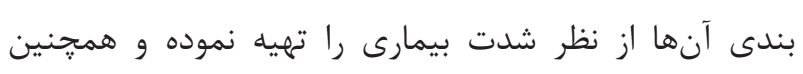
بيمارستانهاى مقصد براى جابجايى بيماران را شناسايى نمايد.

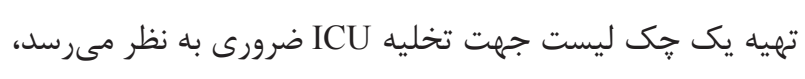

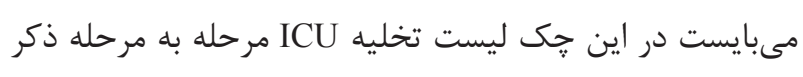

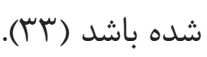

V. ل درخواست امداد براى تخليه اضطرارى

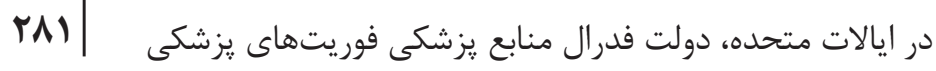

مدت زمان حمل و نقل ضرورى است (• (1). هماهنكى نزديك با

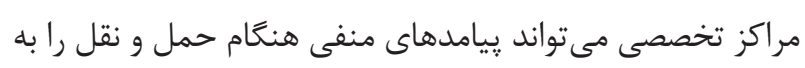

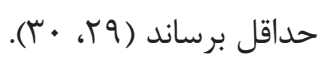

\section{F. تعيين سريرست تيم مراقبتهاى ويزه}

تخليه ايمن و به موقع بخش ICU، مستلزم برخوردارى از دانش

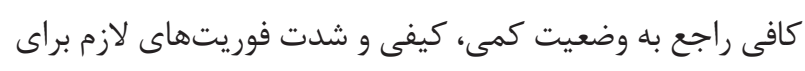

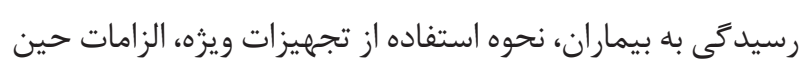

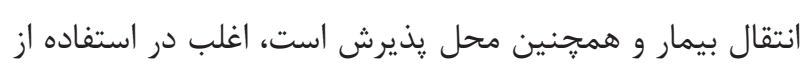

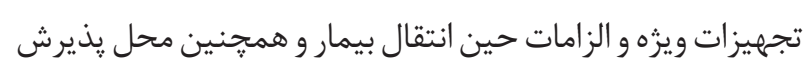

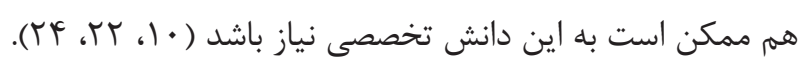

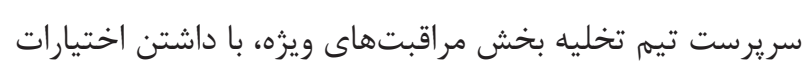

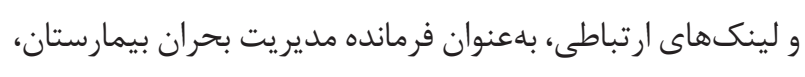

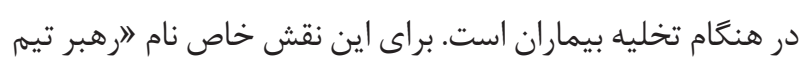

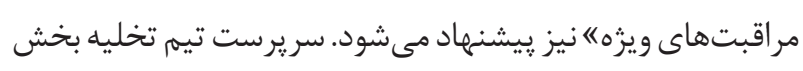

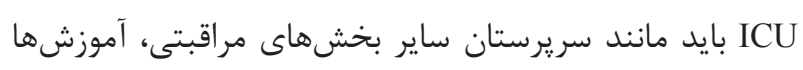
و دورههاى تخصصى ويره اين بخش را كذرانده باشد. بيماران

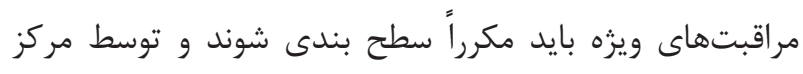

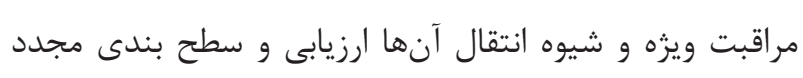

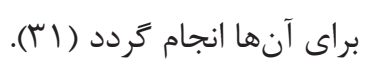
توجه داشته باشيد، برخى بيماران ممكن است نياز به مراقبت إنهاى

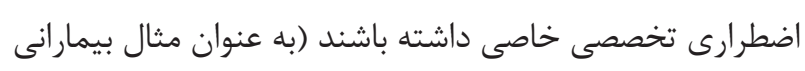
كه از طريق كاناليزاسيون مركزى، اكسيرناسيون غشايى برون داصني

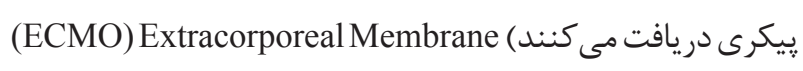

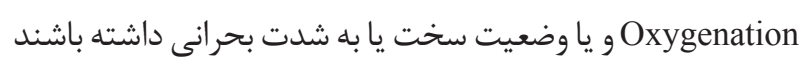
كه نيازمند ارتباط مستقيم بين سريرست تيم تخليه مراقبت ئب

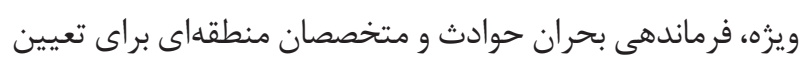
بهترين شرايط تخليه باشند. مانورهاى تخليه بايد براى تمرين

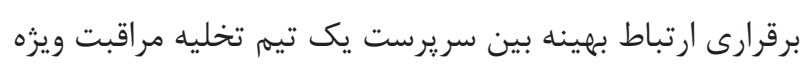

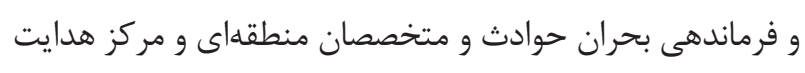
عمليات اضطرارى محلى يا منطقهاى انجام شود (Tr).

ه. انجام سطح بندى بيماران مراقبتهاى ويزه

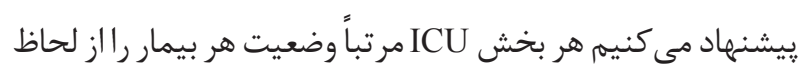




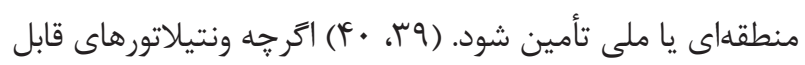

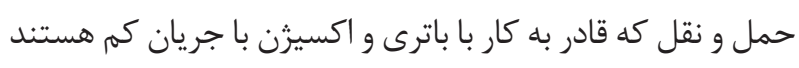

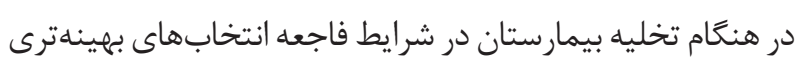
مىباشند، اما ماسك هاى داراى مخزن هوا (Bag Valve Ventilation)

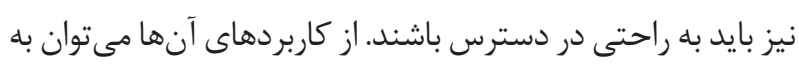

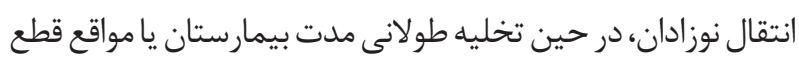
برق ياوقتى كه منبع كميرس كاز در دسترس نيست اشاره كرد (1) (1). با اين حال، معايب ماسك هاى داراى مخزن هوا براى بيماران اينتوبه كيه

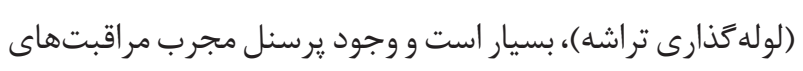

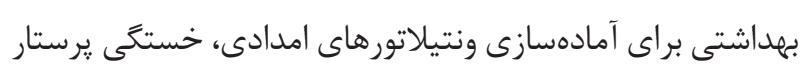
مراقبتهاى بهداشتى در طول كار با ونتيلاتور هاى امدادى، استفاده

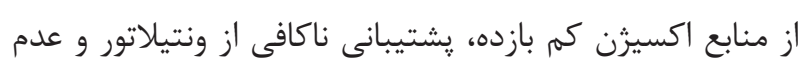
اكسيزن رسانى كافى براى بيماران مبتلا به آسيب حاد شديد آنسي

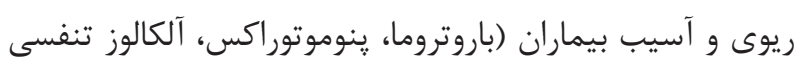

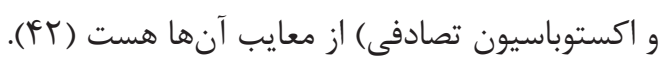

\section{9. اولويت بندى بيماران مراقبتهاى ويزه براى تخليه اضطرارى}

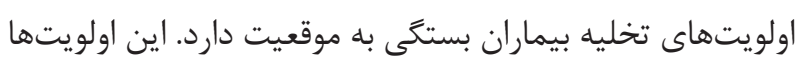
نشان مى دهد كدام يك از بيماران در ابتدا يا انتها منتقل شوند.

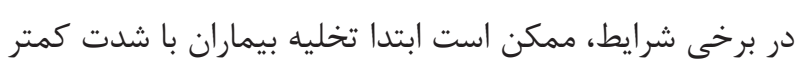
بيمارى مطلوب باشد و در شرايط ديخر، ممكن است ابتدا تخليه

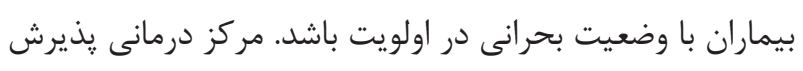

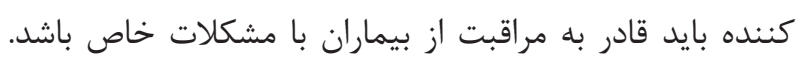
انتخاب يك مركز يذيرش ممكن است با تطبيق يك به يك بيمار

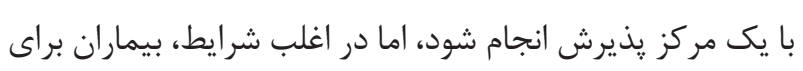

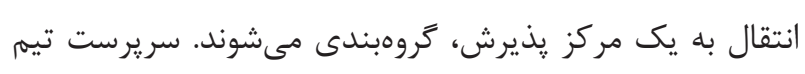

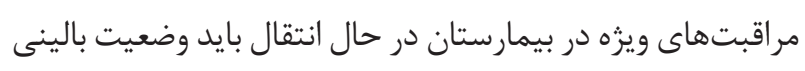

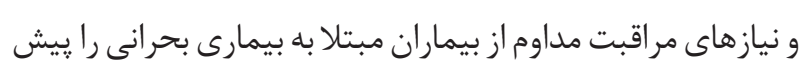

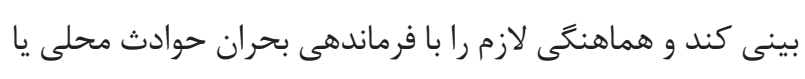

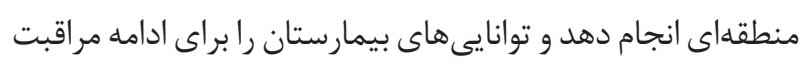

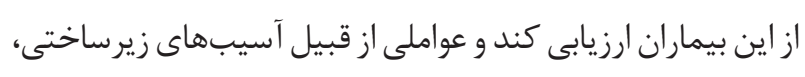

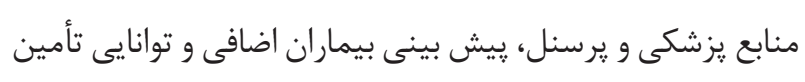

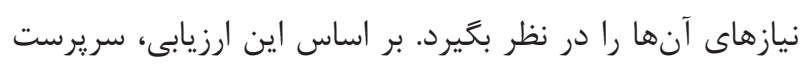
تيم مراقبتهاى ويزه به منظور مطابقت نيازهاى مراقبت از بيمار

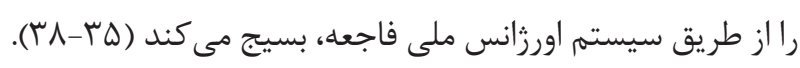
بيمارستان بايد از طريق مديريت اضطرارى محلى درخواست

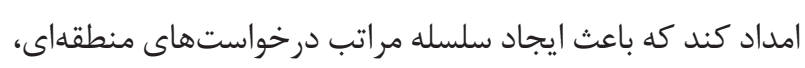

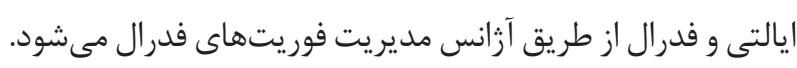

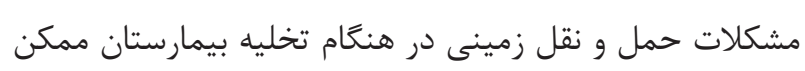

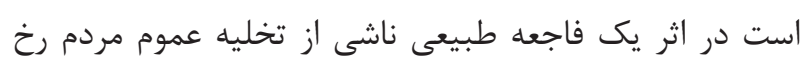

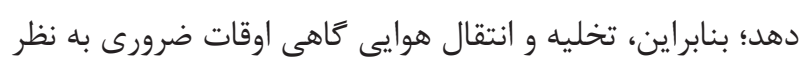
مىرسد. هماهنغى تخليه بيمارستان با دستورات دولت براى تخليه

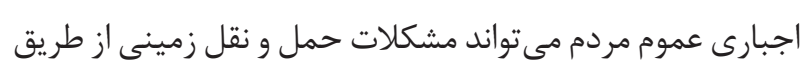

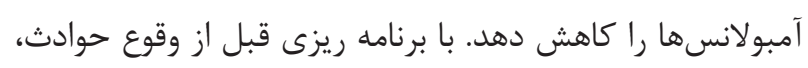

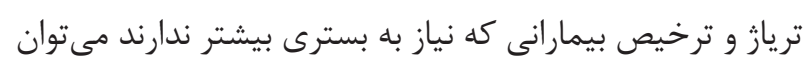

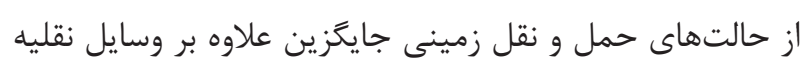

مجرهز شده يزشكى استفاده نمود (سبا).

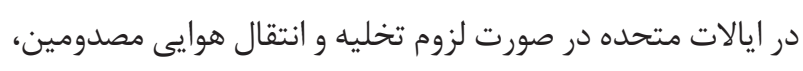

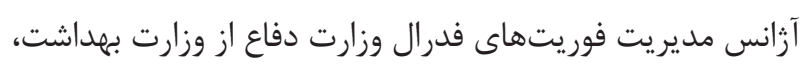

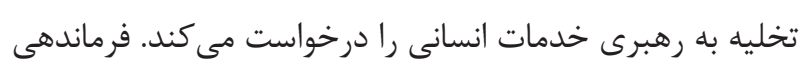

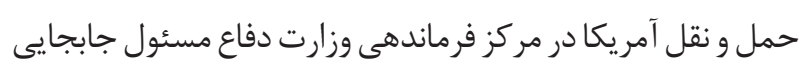
بيماران در سراسر جهان است. فرماندهى حمل و نقل ايالات

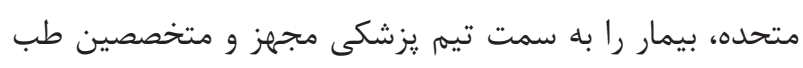

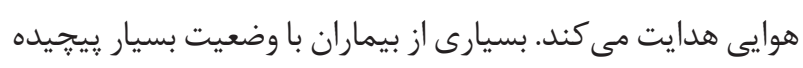
را نمىتوان از طريق اين سيستم كسترده منتقل كرد.

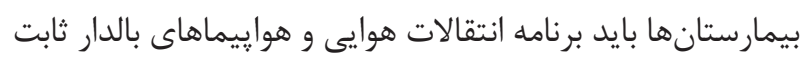

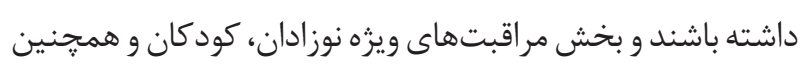

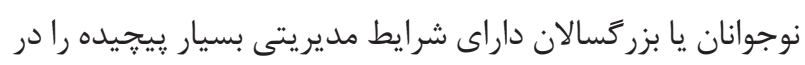

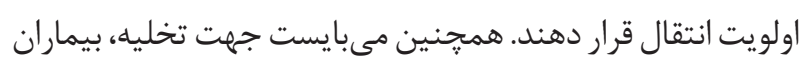
با مشكلات غير تخصصى و بيماران با شرايط غير حاد مشخصاً شناسايى شوند. اين سيستم در ايالات متحده فقط نمونهاى از

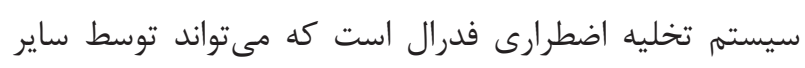

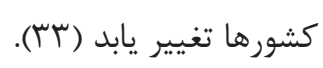

^. اطمينان از تجهيزات تهويه و اكسيثن رسانى و منبع برق مناسب حين حمل و نقل ونتيلاتور و دستخاههاى تنفس مخصوص حمل حمل و نقل نقل براى تخليه

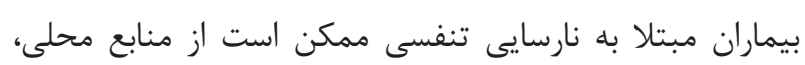


سازى بيمار براى كاهش فشارهاى فيزيولوزيكى نقل و انتقال

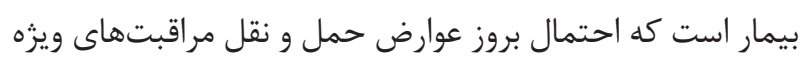

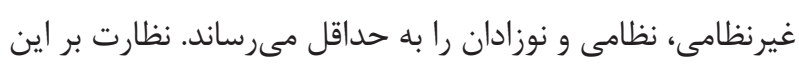

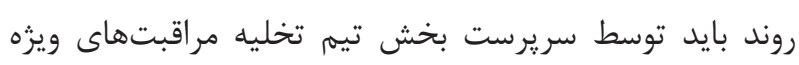

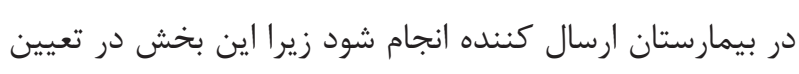

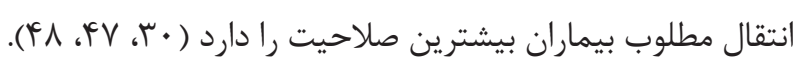
خطر عيب فنى تجهيزات يزشكى در طول حمل و نقل به دليل

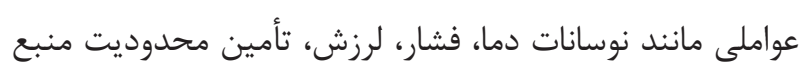
تغذيه الكتريكى و اكسيثن و تداخل الكترومغناطيسى وجود دارد.

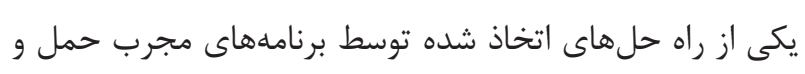
نقل نظامى، تجهيز تيم حمل و نقل با ست لباسهاى إس استاندارد است. تجهيزات تيم حمل و نقل براى بيماران در بيمارستان ارسال

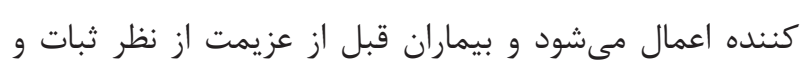

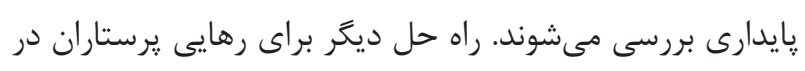

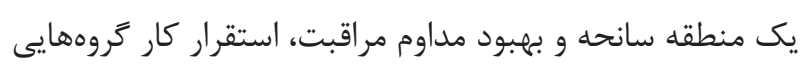

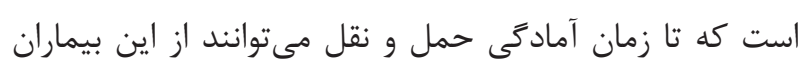

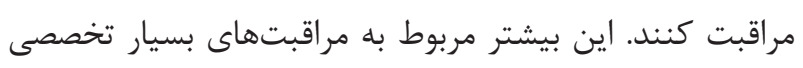

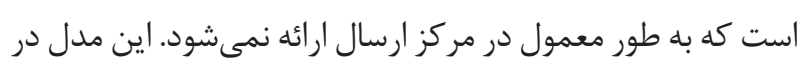
سوانحى مثل مراقبت از سوختخى يا ECMO كه منجر به تلفات

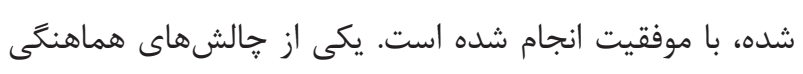

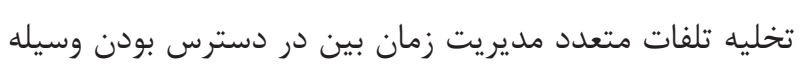

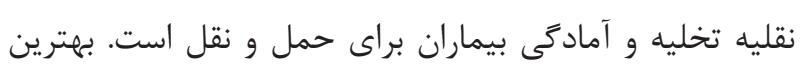

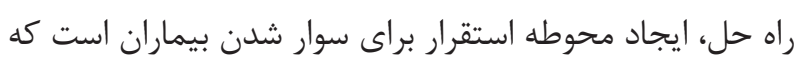
توسط كادر يزشكى مديريت مىشود كه در آماده سازى بيماران



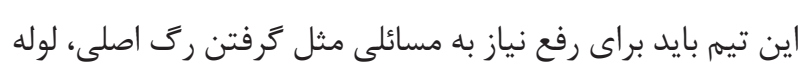

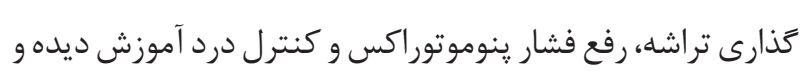

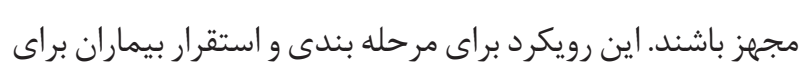
تخليه تلفات متعدد توسط نيروى هوايى ايالات متحده استاندارد

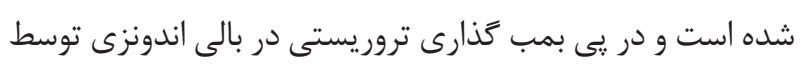
نيروى هوايى استراليا با موفقيت انجام شد.

\section{rا. ارسال اطلاعات مراقبتهاى ويزه بيمار به همراه بيمار}

با منابع و خدمات و در عين حال به حداقل رساندن مسافت حمل

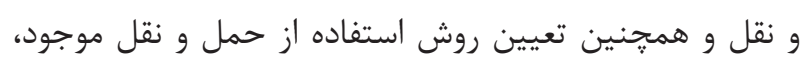

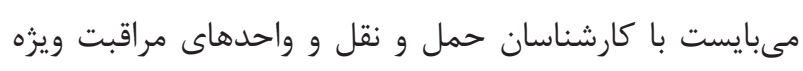
بحرانى منطقهاى همكارى نزديكى داشته باشد (V).

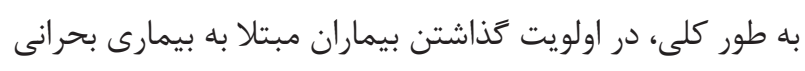

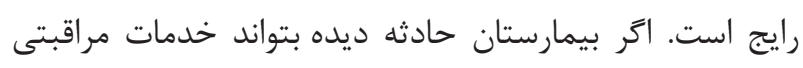
مناسب را ارائه دهد، در حالى كه يرسنل مركز عمليات اضطرارى 1) مكانهاى انتقال (Emergency Operations Center: EOC) شناسايى مى كنند بايد تجهيزات يزشكى هم براى تثبيت سريع

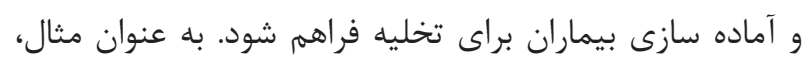

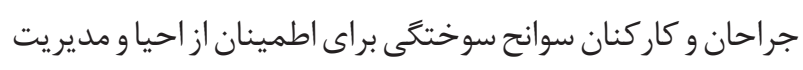

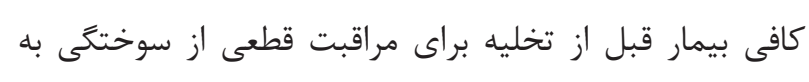

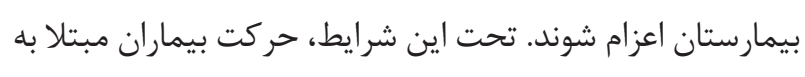
بيمارى بحرانى و كمتر به موازات تثبيت اوليه ممكن است زمان

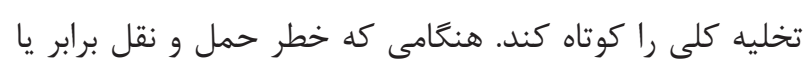
بيشتر از خطر مراقبت از بيمار بحرانى در منطقه فاجعه تلقى شود، ممكن است از بيمار در محل مراقبت شود (9 ؟، باع).

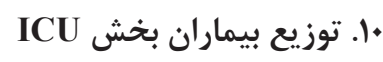

تخليه اضطرارى بيمارستان در هنَام وقوع سوانح يا بلايا در بران ايالات متحده اغلب از طريق الكوهاى ارجاعى موجود با استفاده

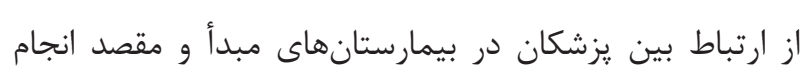
مىشود. با اين حال، اين سيستم ممكن است ناموفق باشد. هنخام

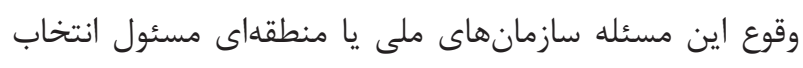

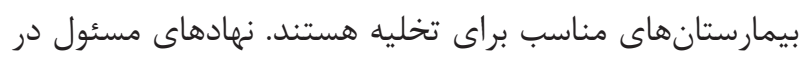
هر كشور متفاوت مىباشند. به عنوان مثال، در انخليس، تخليه

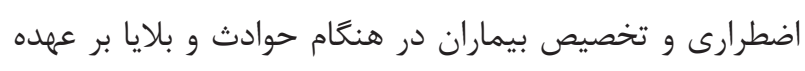
سازمان خدمات ملى سلامت است. در ايالات متحده، خود دولت ايالتى بايد از National Disaster Medical System (NDMS) درخواست كند تا در تخليه بيماران بيمارستانها، به آنها كمك (آنى

كند (FY (

11. آمادهسازى بيمار مراقبتهاى ويزه جهت تخليه از بيمارستان يك رويكرد سيستماتيك در تصميمزيرى براى تخليه و آماده 
بدين ترتيب، اين توزيع بيمار بايد در راستاى همكارى با كميته

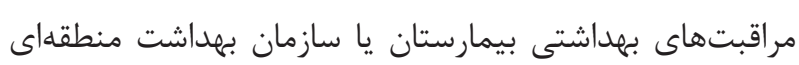

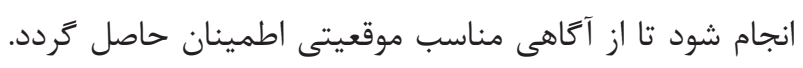

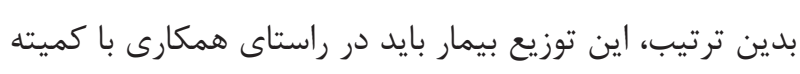

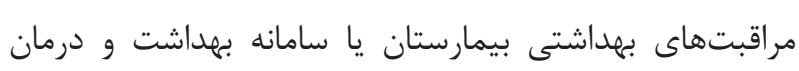

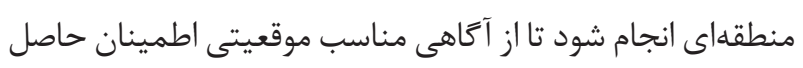

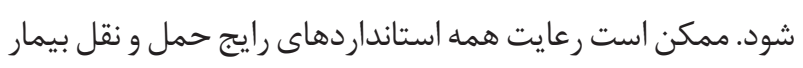

در يك فاجعه امكان يذير نباشد (9). ممكن است در برخى شرايط، براى حمل و نقل از وسايل نقليه

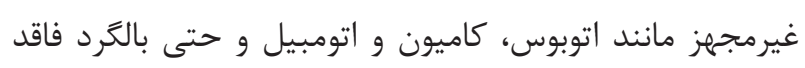
تجهيزات استفاده شود. از سويى ديكر، اگر يك سانحه جادهاى رخ دهد كه عبور از جادهها مختل شده باشد، ممكن است از

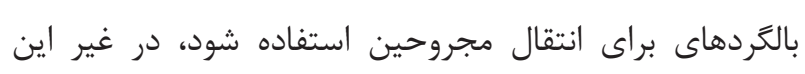

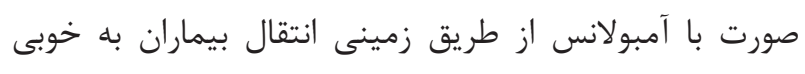
صورت مى گيرد. سيستمهاى رديابى الكترونيكى در سور سوانح

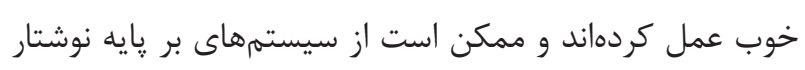

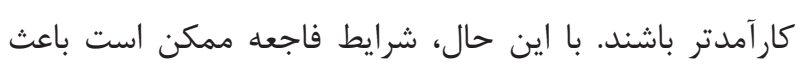

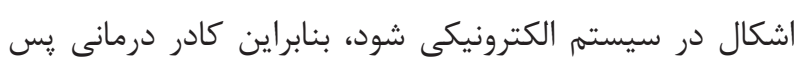

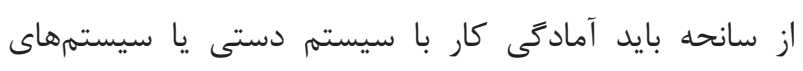

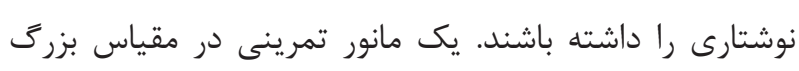

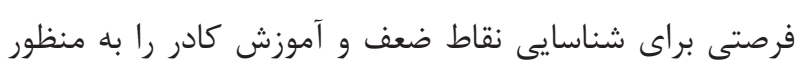

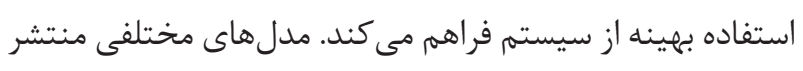

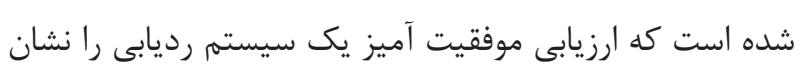

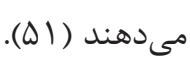

\section{ICU If If رديابى بيماران و تجهيزات}

علاوه بر بيامدهاى بالينى براى رديابى محل بيماران، به همان

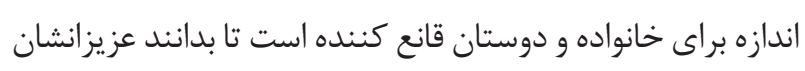
به كجا فرستاده مىشوند. رديابى بيماران يك مكانيزم كارآ آمد وند محسوب مىشود كه از نقطه ترياز اوليه طى سلسله مراتب تخليه تا آخرين بيمارستان يذيرش كننده دنبال مىشود. اين به طبه طور

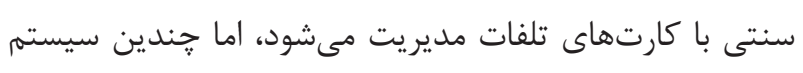

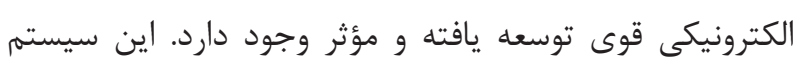

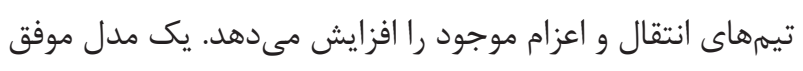

در معرض خطاهاى بزشكى قرار مى دهد. با انتقال كامل سوابق

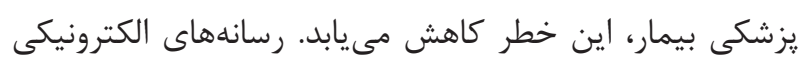

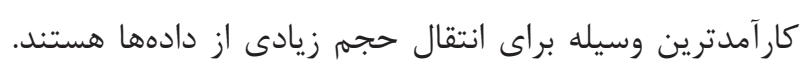

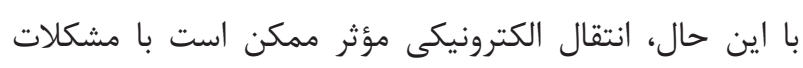

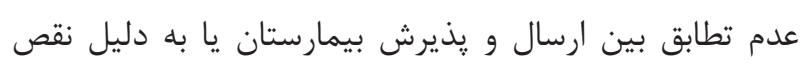

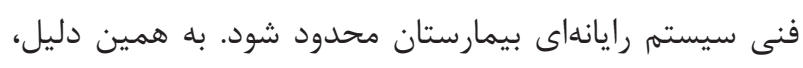
تهيه نسخه يشتيبان از اساسىترين اطلاعات بيمار براى انتقال،

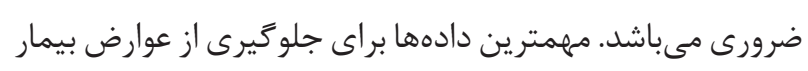

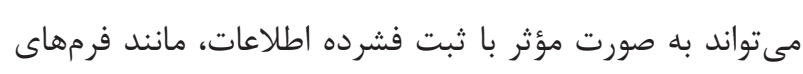

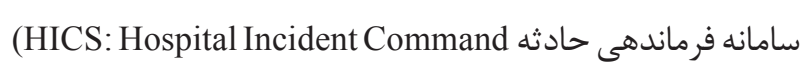
System)

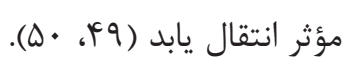

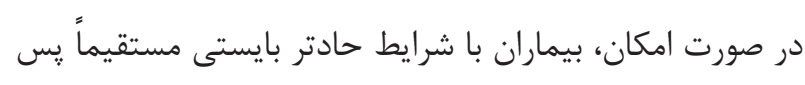

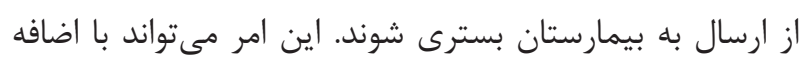

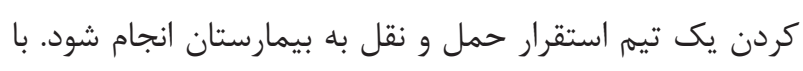

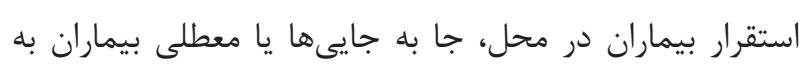

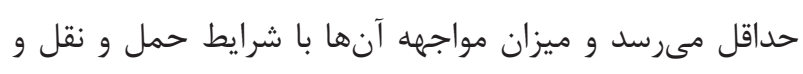

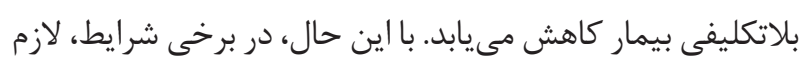

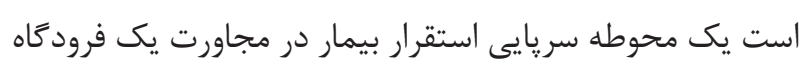

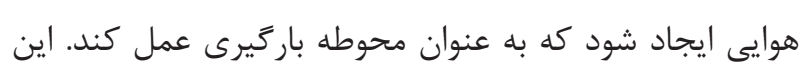

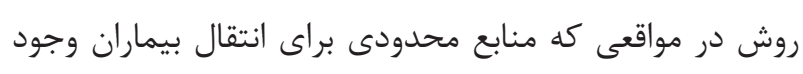

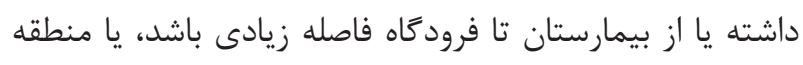

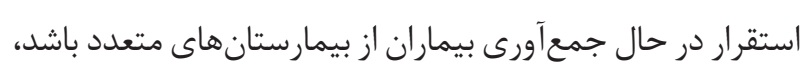
كاربرد بيدا مى كند.

با. انتقال و اعزام بيماران مراقبتهاى ويزه به بيمارستانهاى يذيرنده تنشزدايى سريع منطقه فاجعه، با دسترسى به مراقبتهاى

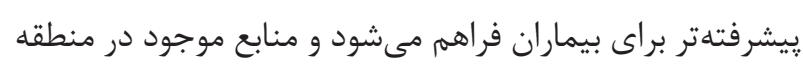
فاجعه را براى بيماران ديكر در دسترس قرار مى دهد. اخر بيماران بدحال، بيمارستان حادثه ديده را اشباع كرده باشند، سريعتر دئرين

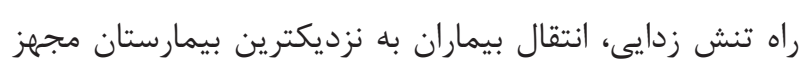

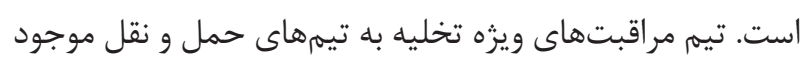
و الكوهاى ارجاع كمك مى كند. 
آكاه بودند، اما فقط 19 نفر (•F د درصد) يك سياست خاص براى

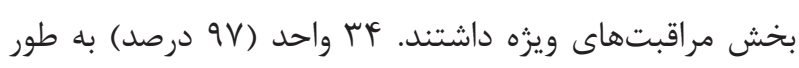

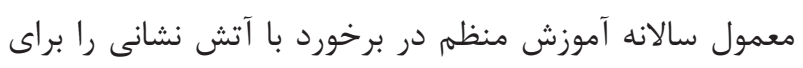

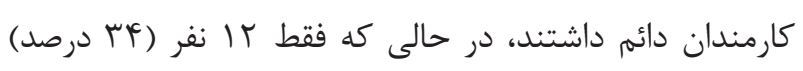

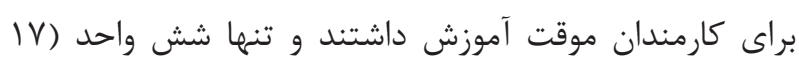

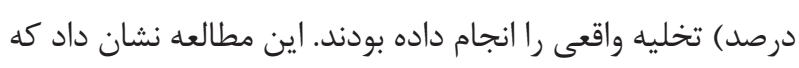

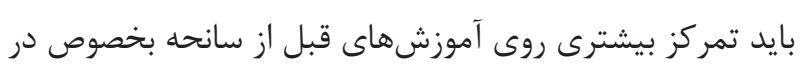

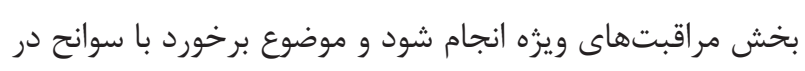
بيمارستانها جدى تر بيخيرى شود (هو).

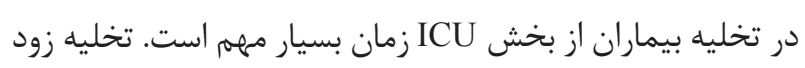

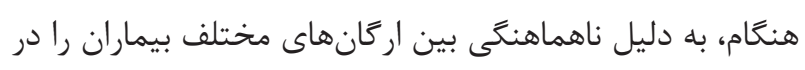
معرض خطر قرار مىدهد، همين طور تخليه ديرهنحام خطرات

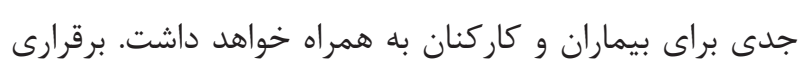

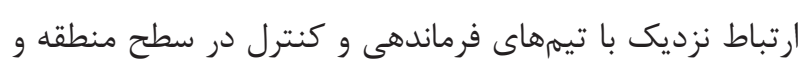

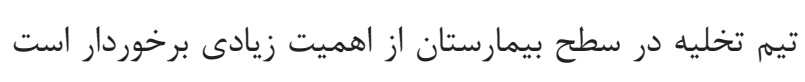

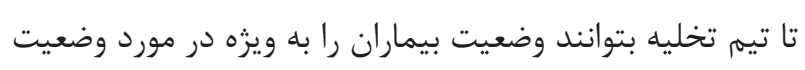

بيماران بدحال اطلاع دهند (بس، بوهان.

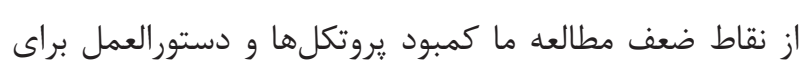
تخليه بيماران از بخش ICU در جهان و همجنين نبود مطالعات

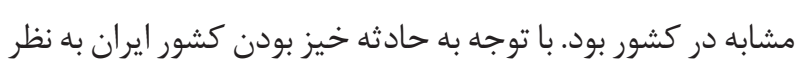

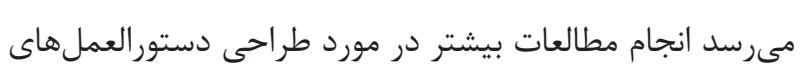

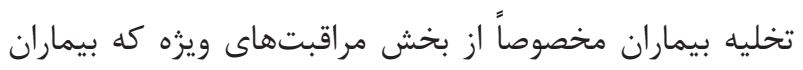
يرخطر در آن بسترى هستند مى تواند كمى كننده باشد.

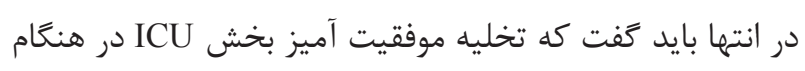

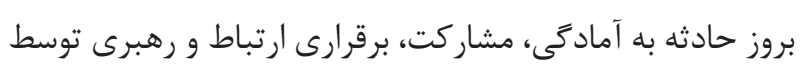

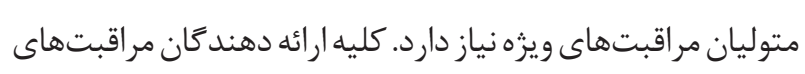
ويزه وظيفه دارند كه مهارتهاى لازم آمادكى و مشاركت در فر فر آ يند

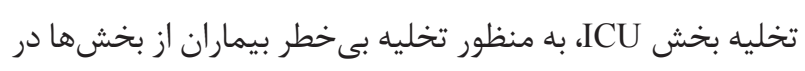

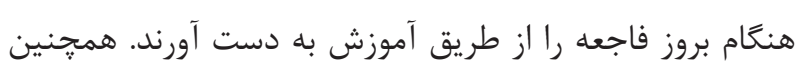
تدوين يروتكل جامع مخصوص بخش ICU هر بيمارستان براى براى

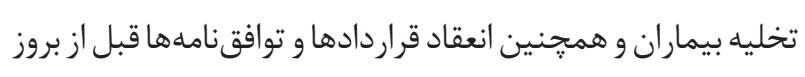

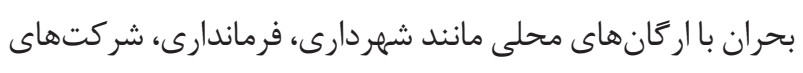

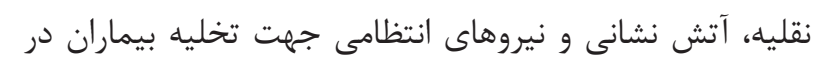

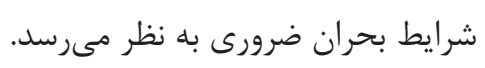

اين استراتزى در گزارشى از عكس العمل به تلفات ناشى از خردباد هاريكان نشان داده شده است.

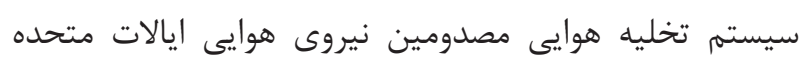

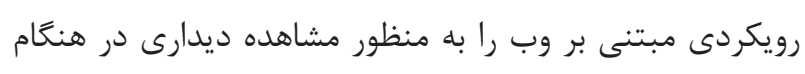

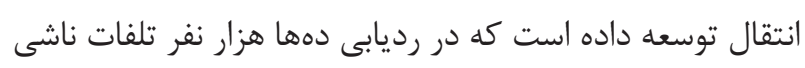

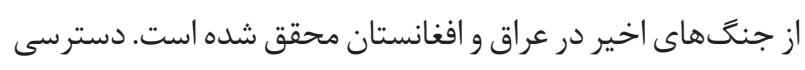
تجهيزات مراقبت از بيمار نيز بايد به دقت رصد شود. همان سيستم رديابى مصدومين رانيز مىتوان براى رديابى تجهيزات مورد نياز

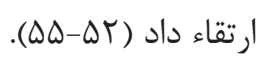

\section{بحث و نتيجه كيرى}

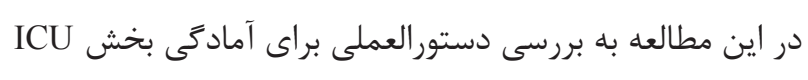

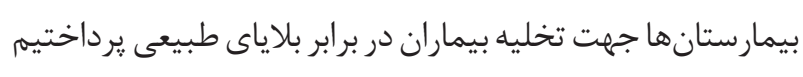

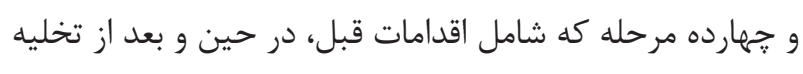

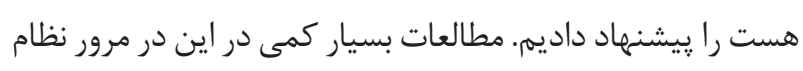

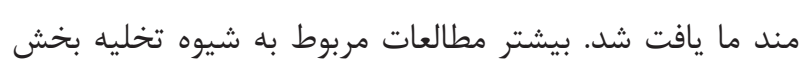

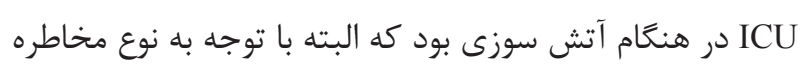

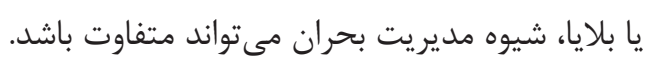

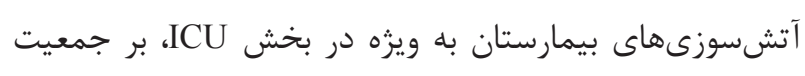

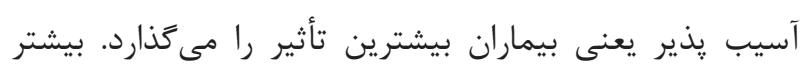

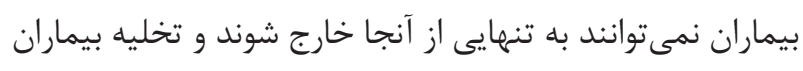

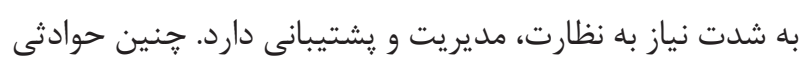

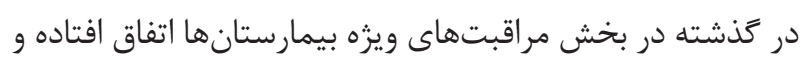

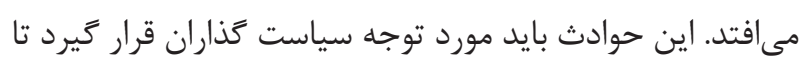

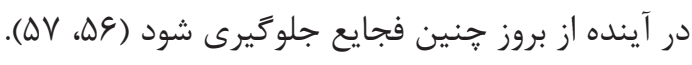

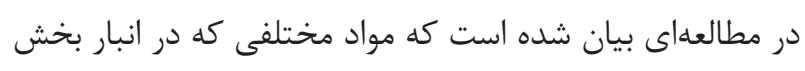

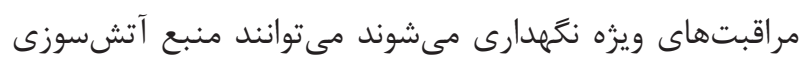

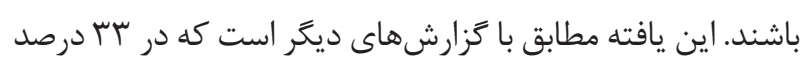

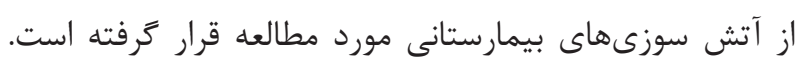

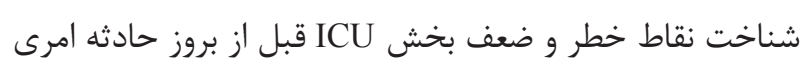

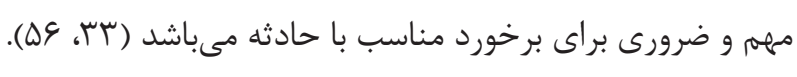

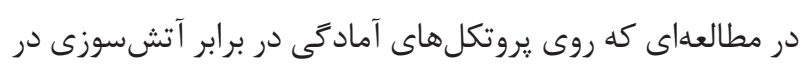

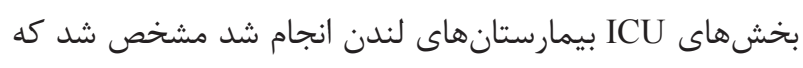
كاركنان r T بخش (19 درصد) از سياست آتش سوزى بيمارستان 


$$
\text { تضاد منافع بدين وسيله كليه نويسند }
$$

\section{References}

1- Flood Management Assessment In Iran Problems And Solutions. In: Badfar M, Doğan E, editors. 2nd International Symposium on Natural Hazards and Disaster Management; 04-06 May 2018; Sakarya-Turkey Sakarya University Culture and Congress Center; 2018.

2- Yamani M, Enayati M. The relation between basins geomorphologic characteristics and flooding potential (analyzing of the flood data by geomorphologic compare of the Fashand and Behjatabad Basins). Geograph Res. 2005;54:47-57.

3- Einav S, Hick JL, Hanfling D, Erstad BL, Toner ES, Branson RD, et al. Surge capacity logistics: care of the critically ill and injured during pandemics and disasters: CHEST consensus statement. Chest. 2014; 146(4 Suppl):e17S-43S. DOI: 10.1378/chest.14-0734 PMID: 25144407

4- Khankeh H, Mohammadi R, Ahmadi F. Health care services at time of natural disasters: a qualitative study. Iran J Nurs. 2007; 20(51): 85-96.

5- Nasiri-Pour A, Raeissi P, Mahbobi M. Border hospital readiness in handling border related crisis in Kermanshah Province, Iran, 2007. J Health Administrat. 2007; 10(28): 41-8.

6- Daugherty EL, Rubinson L. Preparing your intensive care unit to respond in crisis: considerations for critical care clinicians. Crit Care Med. 2011;39(11):2534-9. DOI: 10.1097/ CCM.0b013e3182326440 PMID: 21926569

7- Schultz CH, Koenig KL, Lewis RJ. Implications of hospital evacuation after the Northridge, California, earthquake. N Engl J Med. 2003;348(14):1349-55. DOI: 10.1056/NEJMsa021807 PMID: 12672863

8- Iwashyna TJ, Christie JD, Moody J, Kahn JM, Asch DA. The structure of critical care transfer networks. Med Care. 2009;47(7):787-93. DOI: 10.1097/MLR.0b013e318197b1f5 PMID: 19536030

9- Carlascio D, McSharry M, LeJeune C, Lewis J, Schneider C, Marshall W. Air medical response to the 1990 Will County, Illinois, Tornado. J Air Med Transport. 1991; 10(10): 7-16. DOI: 10.1016/s1046-9095(05)80002-9

10- Fuzak JK, Elkon BD, Hampers LC, Polage KJ, Milton JD, Powers LK, et al. Mass transfer of pediatric tertiary care hospital inpatients to a new location in under 12 hours: lessons learned and implications for disaster preparedness. J Pediatr. 2010; 157(1): 138-43 e2. DOI: 10.1016/j.jpeds.2010.01.047 PMID: 20334875

11- Cryer HG, Hiatt JR, Eckstein M, Chidester C, Raby S, Ernst TG, et al. Improved trauma system multicasualty incident response: comparison of two train crash disasters. J Trauma. 2010; 68(4):
783-9. DOI: 10.1097/TA.0b013e3181d03b8c PMID: 20386274

12- Kanter RK. Regional variation in critical care evacuation needs for children after a mass casualty incident. Disaster Med Public Health Prep. 2012; 6(2):146-9. DOI: 10.1001/dmp.2012.30 PMID: 22700023

13- Stamell EF, Foltin GL, Nadler EP. Lessons learned for pediatric disaster preparedness from September 11, 2001: New York City trauma centers. J Trauma. 2009; 67(2 Suppl): S84-7. DOI: 10.1097/TA.0b013e3181adfb81 PMID: 19667859

14- Gray BH, Hebert K. Hospitals in Hurricane Katrina: challenges facing custodial institutions in a disaster. J Health Care Poor Underserved. 2007;18(2):283-98. DOI: 10.1353/hpu.2007.0031 PMID: 17483558

15- Orlando S, Bernard ML, Mathews P. Neonatal nursing care issues following a natural disaster: lessons learned from the Katrina experience. J Perinat Neonatal Nurs. 2008;22(2):147-53. DOI: 10.1097/01.JPN.0000319102.20593.12 PMID: 18496075

16- Koyama A, Fuse A, Hagiwara J, Matsumoto G, Shiraishi S, Masuno T, et al. Medical relief activities, medical resourcing, and inpatient evacuation conducted by Nippon Medical School due to the Fukushima Daiichi Nuclear Power Plant accident following the Great East Japan Earthquake 2011. J Nippon Med Sch. 2011; 78(6): 393-6. DOI: 10.1272/jnms.78.393 PMID: 22197874

17- Farmer JC, Carlton PK, Jr. Providing critical care during a disaster: the interface between disaster response agencies and hospitals. Crit Care Med. 2006; 34(3 Suppl): S56-9. DOI: 10.1097/01. CCM.0000199989.44467.2E PMID: 16477204

18- Sexton KH, Alperin LM, Stobo JD. Lessons from Hurricane Rita: the University of Texas Medical Branch Hospital's evacuation. Acad Med. 2007; 82(8): 792-6. DOI: 10.1097/ ACM.0b013e3180d096b9 PMID: 17762257

19- Mason WL. The incomplete circle of the National Disaster Medical System: what Arkansas hospitals learned from hurricane Gustav. Biosecur Bioterror. 2010;8(2):183-91. DOI: 10.1089/ bsp.2010.0007 PMID: 20569059

20- Sternberg E, Lee GC, Huard D. Counting Crises: US hospital evacuations, 1971-1999. Prehosp Disaster Med. 2004; 19(2): 1507. DOI: 10.1017/s1049023x00001667 PMID: 15506252

21- Murphy GR, Foot C. ICU fire evacuation preparedness in London: a cross-sectional study. Br J Anaesth. 2011; 106(5): 695-8. DOI: 10.1093/bja/aer033 PMID: 21414979

22- Uppal A, Evans L, Chitkara N, Patrawalla P, Mooney MA, Addrizzo-Harris D, et al. In search of the silver lining: the impact of Superstorm Sandy on Bellevue Hospital. Ann Am Thorac Soc. 
2013; 10(2): 135-42. DOI: 10.1513/AnnalsATS.201212-116OT

PMID: 23607843

23- Taylor I. Hurricane Katrina's impact on Tulane's teaching hospitals. Trans Am Clin Climatol Assoc. 2007; 118:69-78.

24- DeBoisblanc BP. Black Hawk, please come down: reflections on a hospital's struggle to survive in the wake of Hurricane Katrina. Am J Respir Crit Care Med. 2005; 172(10): 1239-40. DOI: 10.1164/ rccm.2509004 PMID: 16275739

25- Gildea JR, Etengoff S. Vertical evacuation simulation of critically ill patients in a hospital. Prehosp Disaster Med. 2005; 20(4): 2438. DOI: 10.1017/s1049023x00002600 PMID: 16128472

26- Manion P, Golden I. Vertical evacuation drill of an intensive care unit: Design, implementation, and evaluation. Disaster Management \& Response. 2004; 2(1): 14-9. DOI: 10.1016/s15402487(04)00010-0

27- Hon KL, Olsen H, Totapally B, Leung TF. Air versus ground transportation of artificially ventilated neonates: Comparative differences in selected cardiopulmonary parameters. Pediatr Emerg Care. 2006; 22(2): 107-12. DOI: 10.1097/01. pec.0000199557.11605.c6 PMID: 16481927

28- Franck L, Epstein B, Adams S. Disaster preparedness for the ICN: Evolution and testing of one unit's plan. Pediatr Nurs. 1993; 19(2): 122-7.

29- Mozingo DW, Barillo DJ, Holcomb JB. The Pope Air Force Base aircraft crash and burn disaster. J Burn Care Rehabil. 2005; 26(2): 132-40. DOI: 10.1097/01.bcr.0000155536.98314.d8 PMID: 15756114

30- Annibale D, Cahill J, Tuttle D, Williford W, Wagner C, Purohit D. Preparation of the critically ill neonate for transport. J South Carolina Med Associat 2002; 98(3): 129-36.

31- Powell T, Hanfling D, Gostin LO. Emergency preparedness and public health: the lessons of Hurricane Sandy. JAMA. 2012; 308(24): 2569-70. DOI: 10.1001/jama.2012.108940 PMID: 23281545

32- Bayard D. Haiti earthquake relief, phase two-long-term needs and local resources. N Engl J Med. 2010; 362(20): 1858-61. DOI: 10.1056/NEJMp1003839 PMID: 20393163

33- King MA, Niven AS, Beninati W, Fang R, Einav S, Rubinson L, et al. Evacuation of the ICU: care of the critically ill and injured during pandemics and disasters: CHEST consensus statement. Chest. 2014; 146(4 Suppl): e44S-60S. DOI: 10.1378/ chest.14-0735 PMID: 25144509

34- Verni C. A hospital system's response to a hurricane offers lessons, including the need for mandatory interfacility drills. Health Aff (Millwood). 2012; 31(8): 1814-21. DOI: 10.1377/ hlthaff.2012.0154 PMID: 22869660

35- Adini B, Laor D, Cohen R, Israeli A. Decision to evacuate a hospital during an emergency: the safe way or the leader's way? J Public Health Policy. 2012; 33(2): 257-68. DOI: 10.1057/ jphp.2012.2 PMID: 22318408

36- Zoraster R, Amara R, Fruhwirth K. Transportation resource requirements for hospital evacuation. American J Disaster Med.
2011; 6(3): 173-86.

37- Sternberg E, Lee GC. New York City's healthcare transportation during a disaster: a preparedness framework for a wicked problem. Prehosp Disaster Med. 2009;24(2):95-107. DOI: 10.1017/ s1049023x00006622 PMID: 19591302

38- Franco C, Toner E, Waldhorn R, Inglesby TV, O'Toole T. The national disaster medical system: past, present, and suggestions for the future. Biosecur Bioterror. 2007; 5(4): 319-25. DOI: 10.1089/ bsp.2007.0049 PMID: 18052820

39- Sprung CL, Zimmerman JL, Christian MD, Joynt GM, Hick JL, Taylor B, et al. Recommendations for intensive care unit and hospital preparations for an influenza epidemic or mass disaster: summary report of the European Society of Intensive Care Medicine's Task Force for intensive care unit triage during an influenza epidemic or mass disaster. Intensive Care Med. 2010; 36(3): 428-43. DOI: 10.1007/s00134-010-1759-y PMID: 20135090

40- Dickson RP, Hotchkin DL, Lamm WJ, Hinkson C, Pierson DJ, Glenny RW, et al. A porcine model for initial surge mechanical ventilator assessment and evaluation of two limited-function ventilators. Crit Care Med. 2011; 39(3): 527-32. DOI: $10.1097 /$ CCM.0b013e318206b99b PMID: 21187747

41- Barkemeyer BM. Practicing neonatology in a blackout: the University Hospital NICU in the midst of Hurricane Katrina: caring for children without power or water. Pediatrics. 2006; 117(5 Pt 3): S369-74. DOI: 10.1542/peds.2006-0099F PMID: 16735267

42- Hanfling D, Altevogt B, Viswanathan K, Gostin L. Committee on guidance for Establishing Crisis Standards of Care for Use in Disaster Situations; Board on Health Sciences Policy (HSP); Institute of Medicine (IOM). Crisis Standards of Care. A Systems Framework for Catastrophic Disaster Response 2012.

43- Cancio LC, Horvath EE, Barillo DJ, Kopchinski BJ, Charter KR, Montalvo AE, et al. Burn support for Operation Iraqi Freedom and related operations, 2003 to 2004. J Burn Care Rehabil. 2005; 26(2): 151-61. DOI: 10.1097/01.bcr.0000155540.31879.fb PMID: 15756117

44- Burns BJ, Habig K, Reid C, Kernick P, Wilkinson C, Tall G, et al. Logistics and safety of extracorporeal membrane oxygenation in medical retrieval. Prehosp Emerg Care. 2011; 15(2): 246-53. DOI: 10.3109/10903127.2010.541976 PMID: 21294633

45- Noah MA, Peek GJ, Finney SJ, Griffiths MJ, Harrison DA, Grieve $\mathrm{R}$, et al. Referral to an extracorporeal membrane oxygenation center and mortality among patients with severe 2009 influenza A(H1N1). JAMA. 2011; 306(15): 1659-68. DOI: 10.1001/ jama.2011.1471 PMID: 21976615

46- Forrest P, Ratchford J, Burns B, Herkes R, Jackson A, Plunkett $B$, et al. Retrieval of critically ill adults using extracorporeal membrane oxygenation: an Australian experience. Intensive Care Med. 2011; 37(5): 824-30. DOI: 10.1007/s00134-011-2158-8 PMID: 21359610

47- Beninati W, Meyer MT, Carter TE. The critical care air transport program. Crit Care Med. 2008; 36(7 Suppl): S370-6. DOI: 


\subsection{7/CCM.0b013e31817e3143 PMID: 18594265}

48- Teichman PG, Donchin Y, Kot RJ. International aeromedical evacuation. N Engl J Med. 2007; 356(3): 262-70. DOI: 10.1056/ NEJMra063651 PMID: 17229953

49- Alm A, Gao T, White D. Pervasive patient tracking for mass casualty incident response. AMIA Annu Symp Proc. 2006: 842.

50- Bouman JH, Schouwerwou RJ, Van der Eijk KJ, van Leusden AJ, Savelkoul TJ. Computerization of patient tracking and tracing during mass casualty incidents. Eur J Emerg Med. 2000; 7(3): 2116. DOI: 10.1097/00063110-200009000-00009 PMID: 11142274

51- Tanaka H, Iwai A, Oda J, Kuwagata Y, Matsuoka T, Shimazu T, et al. Overview of Evacuation and Transport of Patients Following the 1995 Hanshin-Awaji Earthquake. The J Emergency Medicine. 1998; 16(3): 439-44. DOI: 10.1016/s0736-4679(98)00014-6

52- Blake N, Stevenson K. Reunification: keeping families together in crisis. J Trauma. 2009;67(2 Suppl):S147-51. DOI: 10.1097/ TA.0b013e3181af0c13 PMID: 19667849
53- Buono C, Chan T, Killeen J, Huang R, Brown S, Liu F, et al., editors. Comparison of the effectiveness of wireless electronic tracking devices versus traditional paper systems to track victims in a large scale disaster. AMIA Annu Symp Proc; 2007.

54- DeMers G, Kahn C, Buono C, Chan T, Blair P, Griswold W, et al. Secure scalable disaster electronic medical record and tracking system. 2011 IEEE International Conference on Technologies for Homeland Security (HST)2011. p. 402-6.

55- Hamilton J. An internet-based bar code tracking system: coordination of confusion at mass casualty incidents. Disaster Management \& Response. 2003;1(1):25-8. DOI: 10.1016/s15402487(03)70007-8

56- Murphy G, Foot C. ICU fire evacuation preparedness in London: a cross-sectional study. Br J Anaesth. 2011;106(5):695-8. DOI: 10.1093/bja/aer033 PMID: 21414979

57- Wigmore T. Evacuation of the ICU Due to Fire. J Intensive Care Society. 2014;15(4):281-2. DOI: 10.1177/175114371401500403 